\title{
Competitiveness Evaluation of Listed Information Service Companies in China Based on Factor Analysis
}

\author{
Xiaoxue Zhang \\ School of Finance, Guizhou University of Finance and Economics, Guiyang Guizhou \\ 550025, China
}

\begin{abstract}
With the rapid development of information technology in the world, many countries and regions are constantly upgrading their own software information service industry, so that it occupies a favorable position in the industry. Comprehensive ranking of the company has a clear competitive advantage, but also have weak areas; comprehensive ranking company more of the disadvantages, but also competitive in prominent place, so we can put forward relevant countermeasures and suggestions for the information service of Chinese listed company.
\end{abstract}

\section{Keywords}

Information service industry; Competitiveness; Factor analysis; Evaluation

\section{基于因子分析的我国上市信息服务公司 竞争力评价}

\author{
张晓雪 \\ 贵州财经大学金融学院，贵阳 550025, 中国
}

摘要：随着信息技术在全球的快速发展，许多国家与地区都在不断升级自身的软件信息服务 产业，使之在行业中占据有利的地位。综合排名靠前的公司的具有明显的竞争优势，但也有 薄弱的地方; 综合排名靠后的公司劣势较多，但也有竞争力突出的地方，因此可以对我国上 市的信息服务公司提出相关对策与建议。

关键词：信息服务业；竞争力；因子分析；评价

1.引言

1.1. 选题背景与意义
信息服务业是指利用计算机和网 络等现代科学技术对信息资源进行科 学的收集、处理、加工、传输、检 
索、利用, 以信息产品的形式为社会 提供服务并获取利益的一种专门行 业。按照信息服务业所服务的内容, 把该行业分为软件产品业、专业服务 业和信息处理服务业, 80 年代初又增 加第四种行业, 即一体化服务业。系 统集成和网络服务是信息服务业的主 要业务组成。我国的信息服务业尚处 于起步阶段，因此所占信息产业市场 的份额较少。但随着我国信息服务业 的不断推进，预计信息服务业在今后 仍将保持高速发展的态势。

现代信息服务业是一种 “绿色产 业”，其对传统原材料消耗很少。加 大现代信息服务业的投入，对实现经 济的可持续发展有重要作用。随着全 球信息技术的迅猛发展以及互联网的 广泛应用, 使得资源共享变得更加快 捷，信息服务业作为服务业的一部 分, 在我国服务贸易中占据重要地 位, 同时在国民生产总值中的地位也 在不断提高, 成为许多地区的新型主 导行业, 并且成为衡量国家综合国力 与创新能力的重要指标之一。信息服 务业的竞争越来越激烈, 因此十分有 必要探究出一种评价体系, 有助于更 加深入的了解企业竞争力的形成机 理, 寻求我国各个上市信息服务公司 的特点与其合理定位, 找出影响公司 或企业竞争力的因子, 判断其优劣 势, 促进我国信息服务业整体水平的 提高。

\section{2. 研究综述}

迈克尔・波特的《竞争优势》中 指出企业竞争力就等于企业竞争优 势，二者之间区别很小，竞争优势是 竞争性市场中企业绩效的核心，归根 结底产生于企业为客户所能创造的价 值：或者在提供同等效益时采取相对 的低价格, 或者其不同寻常的效益用 于补偿溢价而有余。田巧娣采用聚类 方法将信息服务业的竞争力指标进行
分类篮选，再用因子分析对我国上市 的 62 家企业进行具体的实证分析, 从 偿债能力、获利能力、发展能力、运 营能力、现金运营能力五个方面构造 出信息服务业经济竞争力的评价体 系。高飞认为对信息服务业中小企业 竞争力进行有效评价, 发掘其竞争优 势, 对提升企业整体管理水平, 实现 信息服务业的快速发展至关重要。其 对现代企业竞争力评价方法进行比较 分析的基础上, 采用层次分析法

(AHP) 和 BP 神经网络相结合的评价 方法, 对模型进行实例分析, 用篮选 后的样本数据训练 BP 神经网络, 再用 测试样本验证网络的性能。本文的创 新点在于, 基于前者的研究上, 选取 的样本量较大; 从盈利能力、营运能 力、创新能力、成长能力、偿债能 力、管理能力和现金能力 7 个方面构 建信息服务业的指标体系, 较全面的 评价信息服务公司的竞争力。

\section{3.研究目的与思路}

本文在参考国内外已有的研究成 果基础上, 在国泰安、东方财富网等 网站上收集有关各个上市信息服务公 司公开的财务报表，对我国上市信息 服务企业竞争力的研究, 首先构建了 信息服务企业竞争力指标体系, 在实 证方面, 利用因子分析法得出影响信 息服务企业竞争力的各因子和各因子 的得分与排名, 并计算出其综合排名 来研究上市信息服务公司的竞争力水 平, 促进对信息服务企业竞争力影响 因素的理解, 试图让更多的企业认识 到如何提升信息服务企业的竞争力, 同时为提高竞争力以及参与国际信息 服务竞争提出合理、针对性、可操作 性建议。

\section{2.上市信息服务公司竞争力评价指标选 择与评价方法}




\section{1.指标选择}

本文对信息服务企业竞争力评价 指标采用综合可行的选取方法。其基 本步骤和过程分为以下两个方面:

(1)收集影响信息服务业竞争力度 量指标。在进行相关文献阅读、参考 相似信息服务业竞争力评价指标以及 搜索实证评价指标的基础上, 收集并 整理已归纳总结的评价指标, 分析归 纳各指标体系的共同点和不同处, 再 根据各类指标的可得性, 最终确定本 文的指标选取。

(2)确定信息服务业竞争力评价指 标体系。根据实证分析的最终结果, 看本文评价指标体系是否合理。若存 在不合理的指标, 进行相应指标的修 改并重新利用软件进行分析。

表 2-1 信息服务公司指标体系

\begin{tabular}{|c|c|c|}
\hline & \multirow{4}{*}{ 盈利能力 } & 净资产收益率 X1 \\
\hline & & 净利注 $\mathrm{X} 2$ \\
\hline & & 每股收益 X3 \\
\hline & & 营业收入 X4 \\
\hline & \multirow[t]{2}{*}{ 营运能力 } & 存货周转率 X5 \\
\hline & & 流动资产周转率 X6 \\
\hline & \multirow[t]{2}{*}{ 成长能力 } & 净利润增长率 $\mathrm{x} 7$ \\
\hline \multirow{9}{*}{$\begin{array}{c}\text { 信息服务 } \\
\text { 竞争力指 } \\
\text { 标体系 }\end{array}$} & & 所有者极益增长率 $\mathrm{x} 8$ \\
\hline & 创新能力 & 无形资产占比 X9 \\
\hline & \multirow{3}{*}{ 偿债能力 } & 速动比率 X10 \\
\hline & & 流动比率 X11 \\
\hline & & 现金比率 X12 \\
\hline & \multirow[t]{2}{*}{ 管理能力 } & 管理费用 X13 \\
\hline & & 营业外支出占比 X14 \\
\hline & \multirow{2}{*}{ 现金能力 } & 现金流墨比率 X15 \\
\hline & & $\begin{array}{c}\text { 经营现金净流墨对负债比 } \\
\text { 率 X16 }\end{array}$ \\
\hline
\end{tabular}

\section{2. 评价方法}

本文利用因子分析与分层聚类相 结合的方法, 因子分析是研究如何以 最少的信息丢失将众多原有变量浓缩 成少数几个因子，如何使因子具有一 定的命名解释性的多元统计分析方 法。

\section{3. 上市信息服务公司竞争力实证研究}

\section{1.样本选取与数据来源}

上述本文设定了评价上市信息服 务公司企业竞争力指标体系, 结合我 国信息服务企业的实际情况，在剔除 了代号为 $\mathrm{ST}$ 的公司之后, 选定了 122 家上市信息服务公司为研究样本在国 泰安数据库、东方财富网中收集了 2016 年原始数据信息, 并计算相关指 标。利用软件, 对样本竞争力评价指 标数据进行因子分析, 根据实证分析 所得出的结果, 分析各个公司的在各 因子排名与综合排名, 进行具体解 释。

\section{2. 因子分析实证过程}

在 SPSS22.0 统计软件中, 假定显 著水平为 0.05 进行和 $\mathrm{KMO}$ 和巴特利 特球形检验, 结果显示如表 3-1 所示。

表 3-1 KMO 和巴特利特球形检验图

\begin{tabular}{|c|c|c|}
\hline \multicolumn{3}{|c|}{$\mathrm{KMO}$ 和 Bartlett 的球形度检验表 } \\
\hline 取样足够度的 Kaiser-N & Meyer-Olkin 度量 & 669 \\
\hline \multirow[t]{3}{*}{ Bartlett 的球形度检验 } & 近似卡方 & 1267.562 \\
\hline & df & 120 \\
\hline & Sig. & .000 \\
\hline
\end{tabular}

由表 3-1 所示, 巴特利特球度检验 统计量为 1267.562 , 相应的概率 $\mathrm{P}$ 接 近 0 , 小于显著性水平, 拒绝零假设; $\mathrm{KMO}$ 值为 0.669 , 大于 0.5 ; 可以判断 
出该统指标数据适合做因子分析。采 用主成分分析法提取因子并选取特征 根值大于 1 的特征根, 根据得到的数 据, 提取前 6 个因子进行分析, 这些 公共因子分别解释了总方差的 $21.799 \%$ 、 $17.659 \%$ 、 $11.232 \%$ 、 $9.132 \% 、 7.192 \% 、 6.714 \%$ 、这 6 个因 子的累积贡献率达到 $73.729 \%$, 说明能 够较好地准确地反映出信息服务公司 企业竞争力。并采用方差最大正交旋 转法, 使因子具有命名解释性。根据 旋转之后的因子载荷矩阵, 可以得 出, X7、X8、X10、X11、X12 在第 1 个因子上有较高的载荷, 可以解释为 偿债和成长型因子; X1、X2、X3、 $\mathrm{X} 4$ 在第 2 个因子上有较高的载荷, 可 以解释为市场盈利型因子; X13、X14 在第 3 个因子上有较高的载荷, 可以 解释为资产管理型因子; X15、X16 在 第 4 个因子上有较高的载荷, 可以解 释为现金流量型因子; X9 在第 5 个因 子上有较高的载荷, 可以解释为创新 力因子; X5、X6 在第 6 个因子上有较 高的载荷, 可以解释为资本营运型因 子。运用回归法计算出因子得分系数 矩阵由此得到各个因子得分的计算公 式:

$$
\begin{aligned}
& F_{1=0.03} X_{1-0.18} X_{2-0.014} X_{3} \ldots+0.074 X_{15}+0.018 X_{16} ; \\
& F_{2}=0.315 X_{1}+0.296 X_{2+0.302} X_{3} \ldots+0.029 X_{15}-0.202 X_{16} ; \\
& F_{3}=-0.177^{1} X_{+0.094} X_{2-0.101} X_{3} \ldots+0.499 X_{15}+0.459 X_{16} ; \\
& F_{4=-0.184} X_{1-0.139} X_{2+0.095} X_{3} \ldots-0.031 X_{15}+0.048 X_{16} ; \\
& F_{5}=-0.016 X_{1}+0.014 X_{2-0.027} X_{3} \ldots-0.001 X_{15}-0.078 X_{16} ; \\
& F_{6}=-0.095 X_{1-0.099} X_{2+0.14} X_{3}+\ldots+0.037 X_{15}+0.023 X_{16} ;
\end{aligned}
$$

其中, 为各项指标经处理之后的标准 化数据,再以各因子所对应的方差贡献 率为权数进行加权求和, 即可得到综 合评价得分:

$$
\begin{aligned}
\mathrm{F}= & 0.21879 \mathrm{~F} 1+0.17596 \mathrm{~F} 2+0.10608 \mathrm{~F} 3+0 . \\
& 07713 \mathrm{~F} 4+0.06981 \mathrm{~F} 5+0.06889 \mathrm{~F} 6
\end{aligned}
$$

\section{3. 因子分析研究结论}

根据以上公式计算出各信息服务 公司在各因子上的得分与综合得分。 由评价结果可得, 从综合得分与排名 与各因子得分排名来看, 可以得出影 响上市信息服务公司企业竞争力的主 要因素是偿债和成长型因子、市场盈 利型因子、资产管理型因子、现金流 量型因子、创新力因子、资本营运型 因子, 其中对信息服务公司影响力较 为显著的是偿债和成长型因子、市场 盈利型因子。

(1)分析结果可以说明, 2016 年我 国上市的信息服务的综合竞争力大于 0 的只有 44 家, 占样本总数不到 $1 / 4$, 说明总体竞争力偏低。赢时胜、东软 集团、网宿科技、兆日科技、东软载 波是综合排名前五的信息服务公司, 综合得分分别为 $1.22 、 1.08 、 1.03$ 、 0.85、0.74。其中, 赢时胜凭借其良好 的偿债能力、成长能力以及现金能力 排名第一，而排名倒数第一的佳都科 技综合得分为 -0.21 , 两者之间相差 1.43 分, 差距较为明显。

(2)偿债和成长型因子的因子权重 约为 $21.8 \%$ 。在该因子上得分大于 0 的 信息服务公司共有 42 家, 占总样本量 的 $34.4 \%$, 未到样本量的一半, 说明我 国上市信息服务公司在偿债与成长能 力方面表现最差, 说明缺乏财务安全 的意识与成长潜力。兆日科技、赢时 胜、方直科技是在该因子得分上排名 前三的信息服务公司, 说明这三家公 司的资金流动性较强，财务安全意识 较高; 工大高新、润欣科技、梅安森 是得分排名最后三家公司, 且得分差 距较大，两级分化严重。

(3)市场盈利型因子的因子权重约 为 $17.7 \%$ 。在该因子上得分大于 0 的信 
息服务公司共有 56 家，占总样本的 $45.9 \%$ ，表现尚可。东软集团、网宿科 技、国电南瑞是在该因子得分上排名 前三的信息服务公司, 说明这三家公 司的盈利能力较强。华虹计通、恒生 电子、梅安森是排名最后三家, 这些 公司需改变自己的营销对策, 不断加 强盈利能力。

(4)资产管理型因子的因子权重约 为 $11.2 \%$ 。在该因子上得分大于 0 的信 息服务公司共有 42 家, 占总样本的 $34.4 \%$ ，表现差。恒生电子、用友网 络、中国软件是在该因子得分上排名 前三的信息服务公司, 说明这三家公 司的管理效率较高, 合理利用资源, 减少资金成本。久远银海、银信科 技、京天利是排名最后三家公司, 说 明这 3 家公司的管理效率低下管理成 本较高, 应适当更换管理模式。

(5)现金流量型因子的因子权重为 $7.2 \%$ 。在该因子上得分大于 0 的信息 服务公司共有 62 家, 超过总样本的一 半以上, 说明信息服务公司在现金流 量能力方面表现较好。联络互动、光 环新网、赢时胜是在该因子得分上排 名前三的信息服务公司, 说明这三家 公司的资金利用率较高。金证股份、 浙大网新、银信科技是排名最后 3 家 的公司, 这 3 家公司需要提高自身的 现金利用能力, 增强自身在整个行业 中的竞争力。

(6)创新力因子的因子权重约为 9.1。在该因子上得分大于 0 的信息服 务公司共有 47 家, 占总样本的 $38.6 \%$, 在创新力方面信息服务公司表 现也偏差。启明信息、亿阳信通、科 大讯飞是在该因子得分上排名前三的 信息服务公司, 说明这三家公司的软 实力较强, 对于竞争激烈信息服务公 司来说, 创新能力是现如今评价竞争 力的关键因素。

(7)资本营运型因子的因子权重为 $6.7 \%$ 。在该因子上得分大于 0 的信息
服务公司有 46 家, 占总样本 $37.7 \%$, 表现也较差。博彦科技、东软载波、 东方通是在该因子得分上排名前三的 信息服务公司, 说明这三家公司的营 运能力较强, 汉得信息、国电南瑞、 启明信息是排名最后 3 名的公司, 这 3 家公司需要改善资产的数量与规模, 重视资产的合理配比结合公司自身的 情况, 制定其债偿、盈利等方面的计 划。

\section{4.研究结论}

本文通过对中国上市信息服务公 司竞争力评价指标体系的设计以及具 体的实证分析, 得出影响其竞争力的 6 个因子, 分别是偿债型与成长因子偿 债和成长型因子、市场盈利型因子、 资产管理型因子、现金流量型因子、 创新力因子、资本营运型因子, 影响 信息服务业最重要的因子是偿债型与 成长因子, 通过综合得分与排名, 得 出我国信息服务公司总体的竞争能力 偏弱, 而通过各因子的得分与排名, 找到各公司的优劣势, 可以方便对我 国信息服务公司提出相应对策与建议 来提升其竞争力水平。

\section{参考文献}

[1] 迈克尔波特, 竞争战略, 北京, 华 夏出版社, 1997.

[2] 田巧娣, 我国信息服务业经济竞争 力评价研究, 中国经贸导刊, 2012 .

[3] 高飞, 信息服务业中小企业评价研 究, 合肥工业大学, 2013.

[4] 王天耀, 天津信息服务业竞争力评 价与预测研究--基于经济社会协调 发展的视角, 天津理工大学, 2009.

[5] 关怀庆, 基于主成分分析的我国现 代信息服务业竞争力评价及实证研 究, 物流技术, 2015 . 
[6] 周蕾, 服务业国际竞争力的聚类分 析，科技进步与对策， 2005 .

[7] 胡大立, 企业竞争力论, 北京, 经 济管理出版社, 2001.

[8] 李显君, 企业竞争力形成机理, 数 量经济技术经济研究，2002(10):5760.

[9] 梁小珍, 基于城市金融竞争力评价 的我国多层次金融中心体系, 系统 工程理论与实践, 2011.(10).

[10] 刘沩玮, 基于因子分析和聚类 分析的创业板上市公司综合评价, 财务与金融, 2010 .

[11] 赵弘, 比较视角下的北京信息 服务业竞争力分析, 中国科技论 坛, 2009.

[12] 丁玲华, 我国信息服务业的发 展现状及对策研究, 当代经济管 理, 2011.

[13] 谭安洛, 信息产品、信息市场 的演进与信息服务, 当代经济, 2004.

[14] 金碚, 竞争力经济学, 广州, 广东经济出版社, 2003.

[15] 庞明鉴, 期待企业信息化工作 得到全面推进, IT 时代周刊, 2009. 